\title{
Association Between Sleep Duration, Food Consumption Patterns and Obesity Among
} Adolescents in Qatar

\section{Sara Soliman Abdelfatah Mohamed ${ }^{1}$, Nosheen Zehra Shahid Meer ${ }^{1}$, Saima Sabreen Usman Sheikh ${ }^{1}$ Supervised by: Dr. Abdelhamid Kerkadi ${ }^{1}$, Ms. Joyce Alzalloua Moawad ${ }^{1}$ \\ ${ }^{1}$ Human Nutrition Department, College of Health Sciences, Qatar University, Doha, Qatar}

\begin{abstract}
Background: Recent research suggests that sleep duration contributes towards developing unhealthy dietary habits which can lead to obesity. Further study in this field can provide a new direction in addressing this epidemic.

Objective: To examine the association between sleep duration, food consumption pattern, and obesity in adolescents in Qatar. Hypothesis: Sleep duration and unhealthy dietary pattern may be positively correlated to obesity.

Methods: This is a cross-sectional, descriptive and analytical study including 1161 adolescents aged 14-19 years from a representative sample of independent secondary schools in the state of Qatar. Validated questionnaire was used to collect data on sleep duration and frequency of intake of foods. Sleep duration was classified as short ( $\leq 6 \mathrm{hrs})$, sufficient (7-8 hrs) and long ( $\geq 9 \mathrm{hrs})$. Anthropometric indicators included body weight, height and waist circumference (WC) that were measured using standardized procedures. General obesity was defined according to International Obesity Task Force (IOTF) ageand gender-specific body mass index (BMI) reference values. Agespecific cutoff values for WC were used to define abdominal obesity. Factor loading matrix was used to categorize healthy and unhealthy foods. The association between the study variables was assessed using multiple regression analysis.

Results: The mean frequency of food consumption was lower for students of shorter sleep duration regardless of the day of the week. Students who reported long sleep duration had higher mean frequency of consumption of unhealthy food (fast food, French fries, cakes/donuts, candy/chocolates, sugar-sweetened beverages). Females showed an unhealthier eating pattern as compared to males. Multiple regression analysis revealed that as the WC and BMI increased, consumption of healthy eating pattern decreased by $25 \%$ and $10 \%$ respectively $(p<0.001)$

Conclusion: Lack of sufficient sleep and decreased consumption of healthy foods have an association with increased risk of being obese among adolescents.
\end{abstract}

\section{INTRODUCTION}

besity rates have been remarkably increased over the past decades, with more than 124 million children and adolescents being obese in 2016 alone. Diet quality and excessive food intake has been considered in many studies as a primary factor contributing towards childhood obesity. ${ }^{1}$ Another factor less commonly studied, contributing towards obesity, is sleep duration. Studies show that longer sleep duration was associated with a higher consumption of fresh fruits, vegetables, whole fat milk, water and lower consumption Western fast foods and sweets among obese individuals. ${ }^{2,3}$ Habitual short sleepers ate more than 3 meals a day consuming more sweets and desserts predisposing them to obesity. ${ }^{4}$ This shows that sleep duration contributes towards eveloping unhealthy dietary habits which leads to obesity. Hence, this study is expected to be the first to highlight the crucial role of sleep duration in developing childhood obesity in Qatar.

\section{RESULTS}

Table 1: Prevalence of general and abdominal obesity according to sleep categories.

\begin{tabular}{|c|c|c|c|c|c|c|c|c|}
\hline \multirow{2}{*}{\multicolumn{2}{|c|}{ Sleep Duration }} & \multicolumn{2}{|c|}{ WC } & \multirow{2}{*}{$\begin{array}{c}\mathrm{P} \text { - } \\
\text { value }\end{array}$} & \multicolumn{3}{|c|}{ BMI } & \multirow{2}{*}{$\begin{array}{c}\mathrm{P}- \\
\text { value }\end{array}$} \\
\hline & & Normal & Abdominal & & Normal & Overweight & Obese & \\
\hline \multirow[t]{3}{*}{ Weekday } & Short & 18.0 & 32.0 & & 48.7 & 53.6 & 50.6 & \\
\hline & Sufficient & 10.9 & 20.0 & 0.344 & 31.9 & 30.5 & 28.5 & 0.510 \\
\hline & Long & 7.8 & 11.2 & & 19.4 & 15.9 & 20.9 & \\
\hline \multirow[t]{3}{*}{ Weekend } & Short & 9.8 & 16.9 & & 26.2 & 27.6 & 27.2 & \\
\hline & Sufficient & 9.2 & 19.0 & 0.155 & 27.8 & 29.3 & 28.0 & 0.961 \\
\hline & Long & 17.6 & 27.5 & & 45.9 & 43.1 & 44.8 & \\
\hline
\end{tabular}

Notes: WC= waist circumference; BMI= body mass index; Normal, overweight and obesity according
determined using IOTF reference values; Waist circumference cutoff according to Taylor et al, 2000 .

Figure 1: Frequency of consumption of different foods according to short, sufficient and long sleep duration among subjects during the weekdays.

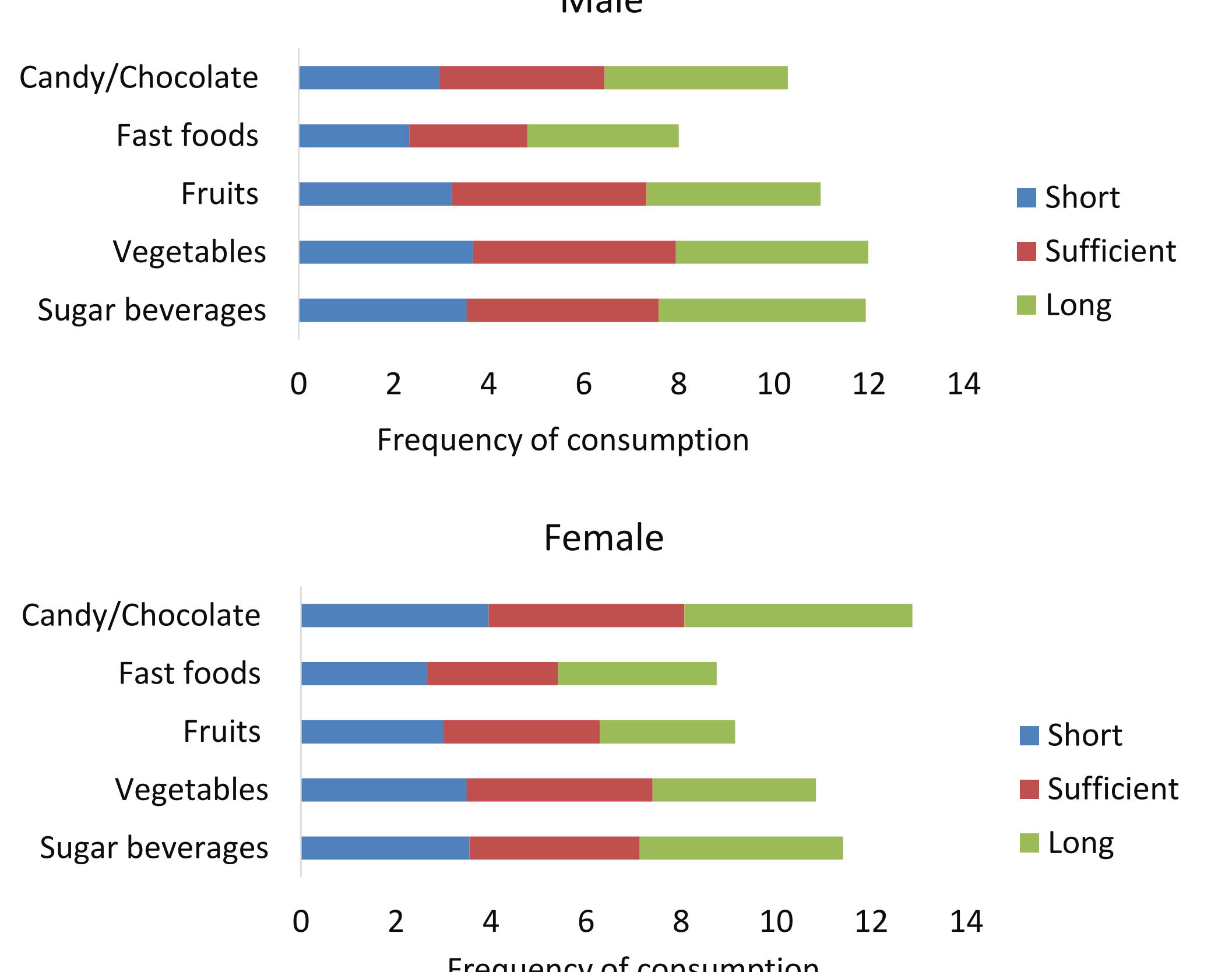

Figure 2: Frequency of consumption of different foods according to short, sufficient and long sleep duration among subjects during the weekend.

Male

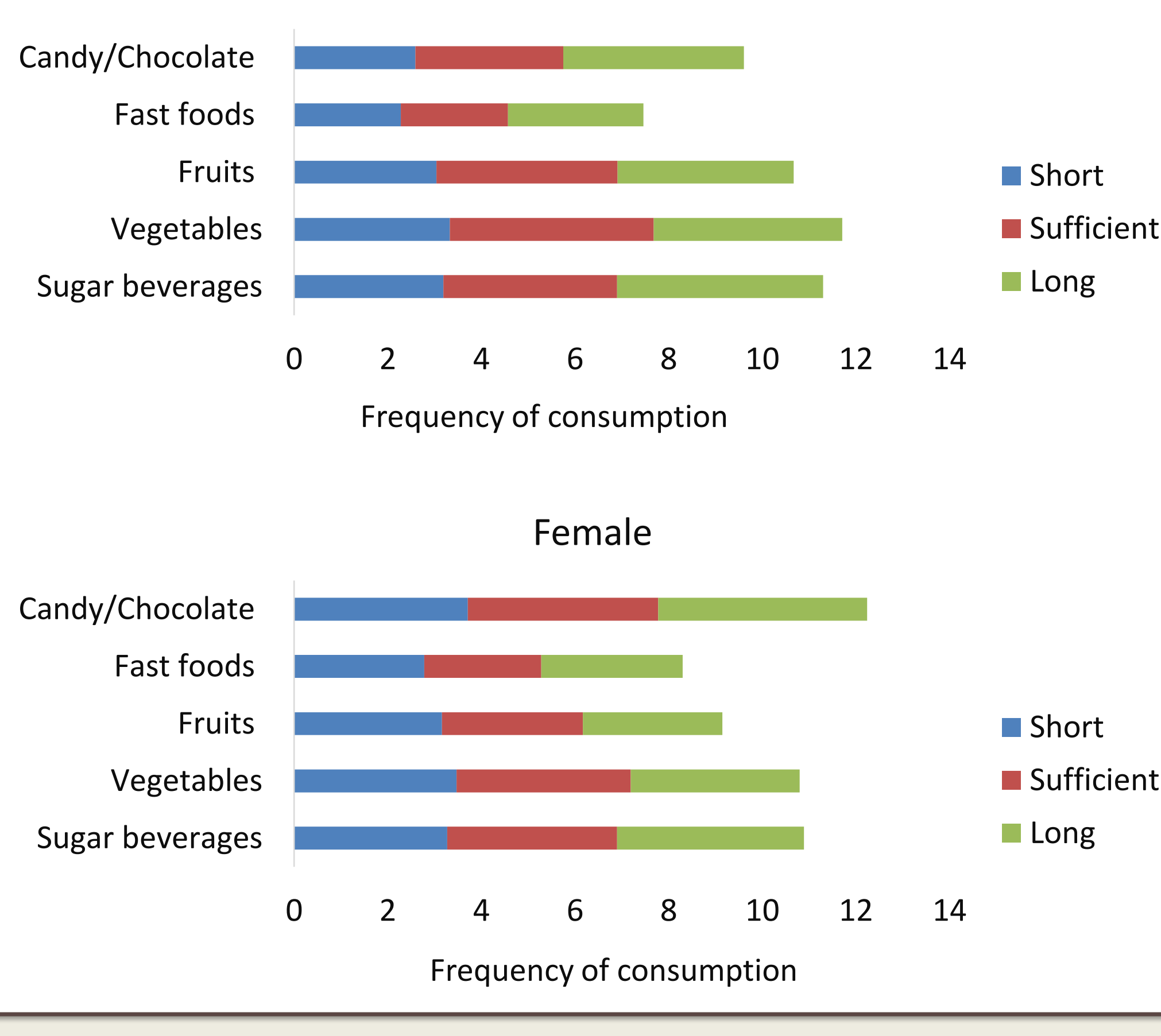

\section{METHODOLOGY}

This is a cross-sectional, descriptive and analytic study, including adolescents from independent secondary schools in the State of Qatar during the academic year 2013-2014.

\section{Dimensions and Structure}

Selection was done through two sampling stages; first being random school selection and second random class selection.

\section{The Sample}

The final sample consisted of 1161 students, aged between 14 and 19 years. For data analysis, the subjects were divided into two groups based on their age; 14-16 years and 7-19 years. The sample selection was controlled and included only those who were free from any physical abnormalities. Written consent was obtained from all participants.
Anthropometric measurements

Weight, height, waist circumference (WC) and BMI were measured using standard methods and calibrated tools. Overweight and obesity among 1417 year adolescents were defined using IOTF age- and gender-specific BMI reference values. WHO standards were used to define for adolescents aged 18-19 years i.e. $\mathrm{BMI}=25$ to $29.9 \mathrm{~kg} / \mathrm{m}^{2}$ and $\mathrm{BMI}>30 \mathrm{~kg} / \mathrm{m}^{2}$ for overweight and obese respectively. The criteria used to define abdominal obesity were gender- and agespecific WC values associated with high trunk fat measured by DEXA.

\section{Lifestyle Measurements}

Data about lifestyle measurements were collected using Arab Teens Lifestyle Study (ATLS) questionnaire. It included 10 questions addressing the frequency of consuming healthy and unhealthy foods and two questions regarding sleep duration.
Sleeping hours were classified as short for less than 6 hours, sufficient as $7-8$ hours and long as 9 hours and more based on the recommendations from National Sleep Foundation for the age group, 14-19 years. ${ }^{5}$

Statistical analysis

Test, ANOVA and Pearson's square test tested the association between the three variables, independently of other confounding factors. P value $<0.05$ was considered significant. Multiple inear regression analysis of variance detected the relationship between (i) obesity indicators (WC and BMI), (ii) eating patterns (healthy and unhealthy) and (iii) sleep duration (sufficient and Healthy and unhealthy pattern was defined using factor loading matrix. All statistical analysis was performed using STATA version 15.0 and SPSS version 25.0
Table 2: Multiple linear regression analysis between the indicators of obesity, Dietary pattern Sleep duration.

\begin{tabular}{|c|c|c|c|c|c|c|}
\hline & \multicolumn{3}{|c|}{$W C^{a}$} & \multicolumn{3}{|c|}{$B M I^{a}$} \\
\hline & B & $95 \% \mathrm{Cl}$ & $\begin{array}{c}P \\
\text { value }\end{array}$ & B & $95 \% \mathrm{Cl}$ & $\begin{array}{c}P \\
\text { value }\end{array}$ \\
\hline $\begin{array}{l}\text { Healthy } \\
\text { Pattern }\end{array}$ & -2.528 & $\begin{array}{l}(-3.417)- \\
(-1.638)\end{array}$ & 0.000 & -1.098 & $\begin{array}{l}(-1.489)- \\
(-0.707)\end{array}$ & 0.000 \\
\hline $\begin{array}{l}\text { Unhealthy } \\
\text { Pattern }\end{array}$ & 0.039 & $\begin{array}{l}(-0.862)- \\
(0.939)\end{array}$ & 0.933 & -0.282 & $\begin{array}{l}(-0.678)- \\
(0.114)\end{array}$ & 0.162 \\
\hline $\begin{array}{l}\text { Sufficient } \\
\text { Sleep } \\
\text { Duration }\end{array}$ & -1.181 & $\begin{array}{l}(-3.201)- \\
(0.838)\end{array}$ & 0.251 & -0.245 & $\begin{array}{l}(-1.133)- \\
(0.642)\end{array}$ & 0.588 \\
\hline $\begin{array}{l}\text { Long Sleep } \\
\text { Duration }\end{array}$ & 0.157 & $\begin{array}{l}(-2.219)- \\
(2.534)\end{array}$ & 0.897 & 0.364 & $\begin{array}{l}(-0.681)- \\
(1.409)\end{array}$ & 0.495 \\
\hline
\end{tabular}

Notes: $W C=$ waist circumference; $B M I=$ body mass index; $\beta=$ beta coefficient; $C \mathrm{Cl}$ confiden
interval. ${ }^{\circ}$ Obesity variables have been corrected for age, gender and physical activity

\section{CONCLUSION}

The present study revealed an inverse relationship of obesity indicators with healthy eating pattern and sufficient sleep duration among adolescents.

\section{REFERENCES}

Gungor NK. Overweight and obesity in children and adolescents. J Clin Res Pediatr Endocrinol. 2014;6(3):129-143.

Gong QH, Li H, Zhang XH, Zhang T, Cui J, Xu GZ. Associations between sleep duration and physical activity and dietary behaviors in Chinese adolescents: results from the Youth Behavioral Risk Factor Surveys of 2015. Sleep Med. 2017;37:168-173.

3. Perez-Farinos N, Villar-Villalba C, Lopez Sobaler AM, et al. The relationship between hours of sleep, screen time and frequency of food and drink consumption in Spain in the 2011 and 2013 ALADINO: a cross-sectional study BMC Public Health. 2017;17(1):33.

4. Dashti HS, Scheer FA, Jacques PF, Lamon-Fava S, Ordovas JM. Short sleep duration and dietary intake: epidemiologic evidence, mechanisms, and health implications. Adv Nutr. 2015;6(6):648-659.

Hirshkowitz M, Whiton K, Albert SM, et al. National Sleep Foundation's sleep time duration recommendations: methodology and results summary. Sleep Health. 2015;1(1):4043.

\section{ACKNOWLEDGEMENTS}

The authors would like to appreciate the adolescents for thei cooperation with the study team. We would also like to thank the Ministry of Education and Higher Education (MOE) and the Ministry of Public Health (MOPH) for their coordination in carrying out the research and permitting the collection of data from independen secondary schools of Qata.

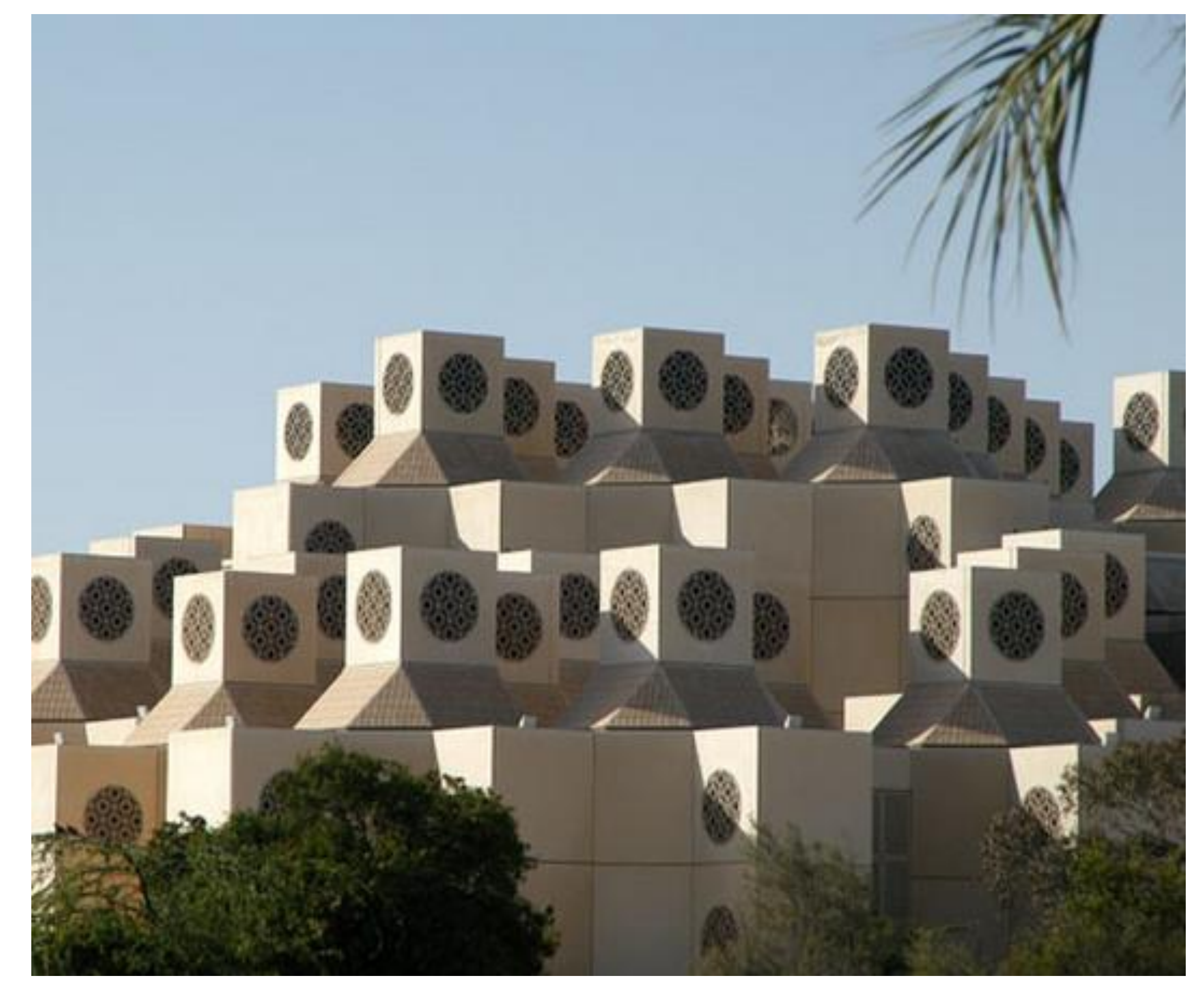

